\title{
LITERASI MEDIA UNTUK MENGANTISIPASI BERITA PALSU $(H O A X)$ DI MEDIA SOSIAL BAGI MASYARAKAT PULAU TIDUNG KEPULAUAN SERIBU
}

\author{
Aulia Rahmawati ${ }^{1)}$, Krisanjaya ${ }^{2)}$ \\ Fakultas Bahasa dan Seni, Universitas Negeri Jakarta \\ E-mail: aulia.rahmawati@gmail.com ${ }^{1)}$,ksanjaya@ yahoo.com ${ }^{2)}$
}

\begin{abstract}
Community Service is carried out by donating Training to Anticipate Fake News (Hoax) on Social Media, which is a pro-active form and participation of Universities in the Thousand Islands Police Resort program through the local government in overcoming the problem of media literacy (dissemination of hoax news), so that people can distinguish which information is correct and which information is fake or hoax so that the acceleration and effectiveness of development programs can be achieved which is marked by the better quality of public understanding related to false information (hoax) on social media. Media Literacy Training Anticipating Fake News (Hoax) in Social Media uses the Empowering 8 (E8) model approach. Post test results from 26 participants who took part in the training, there was a significant increase in value, namely as many as 26.56 points from the average value of the pre test value of 55 points with a value range of 20 to 70 points, to 74.56 points with a value range of 60 to 80 points .
\end{abstract}

Keywords: media literacy, fake news, hoax;

\section{Abstrak}

Pengabdian kepada masyarakai ini dilaksanakan dengan mengadakan Pelatihan Literasi Media Mengantisipasi Berita Palsu (Hoax) Di Media Sosial, yang merupakan wujud pro aktif dan partisipasi Perguruan Tinggi terhadap program Polres Kepulauan Seribu melalui pemerintah setempat dalam mengatasi persoalan literasi media (penyebaran berita hoax), agar masyarakat bisa membedakan mana informasi yang benar dan mana informasi yang palsu atau hoax sehingga dapat tercapai akselerasi dan efektivitas program pembangunan yang ditandai oleh semakin baiknya kualitas pemahaman masyarakat terkait informasi yang palsu (hoax) pada media sosial. Pelatihan Literasi Media Mengantisipasi Berita Palsu (Hoax) Di Media Sosial menggunkan pendekatan model Empowering 8 (E8). Hasil post test dari 26 peserta yang mengikuti pelatihan, terdapat peningkatan nilai yang cukup signifikan, yakni sebanyak 26.56 poin dari nilai rata-rata nilai pretest adalah 55 poin dengan rentang nilai 20 s.d 70 poin, menjadi 74.56 poin dengan rentang nilai 60 s.d 80 poin.

Kata Kunci: literasi media, berita palsu, hoax;

\section{PENDAHULUAN}

Pemerintahan

Administrasi

sebagaimana

Kepulauan dikutip

Kabupaten

harianumum.com telah memfokuskan sektor pariwisata sebagai andalan sumber penghasilan asli daerah (PAD) selain sektor-sektor lainnya dengan menjadikan Pulau Tidung sebagai pilot project guna mendongkrak kunjungan wisata di Kepulauan Seribu.
Penggunaan media sosial sebagai bagian dari upaya pemerintah setempat mempromosikan daerah-daerah wisata di kepulauan seribu berdampak positif dengan meningkatnya kunjungan wisata ke Pulau Tidung. Hal ini dapat terlihat dengan peningkatan jumlah sarana homestay yang hingga saat ini jumlahnya telah mencapai sekitar 300 unit.

Kehadiran media sosial bukan hanya berdampak positif dengan 
perkembangan teknologi informasi bagi masyarakat, namun juga sebaliknya dapat membawa dampak negatif jika tidak dikelola dengan bijak. Kemajuan teknologi di era globalisasi membuat informasi begitu cepat beredar luas sehingga kini media sosial dipenuhi berita informasi palsu (hoax), provokasi, fitnah, sikap intoleran. Keberadaan internet sebagai media online membuat informasi yang belum terverifikasi benar dan tidaknya tersebar dengan cepat. Hanya dalam hitungan detik, suatu peristiwa sudah bisa langsung tersebar dan diakses oleh pengguna internet melalui media sosial.

Melalui media sosial, ratusan bahkan ribuan informasi disebar setiap harinya. Bahkan orang kadang belum sempat memahami materi informasi, reaksi atas informasi tersebut sudah lebih dulu terlihat.

Salah satu contoh begitu cepatnya penyebaran berita hoax melalui media sosial adalah berita terkait pernyataan Ahok soal surat Al Maidah di kepulaun Seribu yang memicu perdebatan antar pengguna media sosial sehingga dapat berdampak pada makin maraknya kemunculan berita hoax.

Masyarakat sebagai konsumen informasi bisa dilihat masih belum bisa membedakan mana informasi yang benar dan mana informasi yang palsu atau hoax belaka. Beberapa faktor mempengaruhi terjadinya hal ini diantaranya yaitu ketidaktahuan masyarakat dalam menggunakan media sosial secara bijaksana karena didukung oleh tingkat pendidikan mayoritas tertinggi hanya tingkat SMA. Dengan mengatasnamakan kebebasan para pengguna internet dan media sosial khususnya banyak netizen yang merasa mempunyai hak penuh terhadap akun pribadi miliknya. Mereka merasa sahsah saja untuk menggunggah tulisan, gambar atau video apapun ke dalam akunnya. Meskipun terkadang mereka tidak sadar bahwa apa yang mereka unggah tersebut bisa saja melanggar etika berkomunikasi dalam media sosial.

Dalam konteks semacam itu, yang harus dilakukan adalah fokus pada persebaran informasi palsu, bukan hanya melakukan pembatasan atau pemblokiran, melainkan lebih kepada bagaimana mengembangkan literasi masyarakat agar lebih bijak dalam memanfaatkan media sosial. David Considine (dalam The Journal of Media Literacy, Volume 41, Number 2) memberikan definisi media literacy sebagai“"The ability to access, analyze, evaluate and communicate information in a variety of format including print and nonprint". Dalam pandangan David Considine, masyarakat yang sudah mengalami Media Literacy atau masyarakat yang sudah melek media, adalah masyarakat yang memiliki kemampuan untuk mengakses, menganalisis, mengevaluasi dan mengkomunikasikan informasi dalam berbagai format pesan yang disampaikan oleh media massa, baik itu cetak maupun elektronik.

Maraknya berita palsu atau bohong yang belum tentu kebenaranya (berita hoax) yang beredar di media cetak, media online, media elektronik bahkan hingga bermunculan di sosial media dapat memecah persatuan dan kesatuan bangsa Indonesia.

Douglas Kellner dalam bukunya "Budaya Media: Cultural Studies, Identitas dan Politik, antara Modern dan Postmodern" menyampaikan bahwa terdapat satu cara yang dapat digunakan untuk menciptakan masyarakat yang cerdas dalam menggunakan media atau masyarakat yang melek media, yaitu dengan menggunakan budaya mereka sendiri (kearifan lokal) yang merupakan 
manifestasi dari ajaran-ajaran budaya yang dihidupi oleh suatu masyarakat lokal, yang dapat digunakan sebagai filter untuk menyerap dan mengolah kebudayaan asing sesuai watak dan kemampuan sendiri. Budaya asing di sini termasuk budaya-budaya asing yang terpublikasi ke masyarakat melalui media massa.

Penanganan penyebaran berita hoax menjadi penting karena merupakan wujud pro aktif dan partisipasi Perguruan Tinggi terhadap program Polres Kepulauan Seribu melalui pemerintah setempat dalam mengatasi persoalan literasi media (penyebaran berita hoax), agar masyarakat bisa membedakan mana informasi yang benar dan mana informasi yang palsu atau hoax yakni dengan melaksanakan

pengabdian masyarakat di Pulau Tidung Kepulauan Seribu berupa Pelatihan Penerapan metode literasi media berbasis kearifan lokal dengan mengadopsi model yang dikembangkan dari hasil penelitian Vibriza Juliswara pada tahun 2017 dengan judul "Mengembangkan Model Literasi Media yang Berkebhinnekaan dalam Menganalisis Informasi Berita Palsu (Hoax) di Media Sosial.

\section{METODE PELAKSANAAN}

Pelaksanaan Kegiatan dilaksanakan melalui 2 (dua) tahap, yakni:

a) Tahap pertama Persiapan, yang meliputi persiapan meliputi:

1. Penetapan Lokasi

Penetapan lokasi yang ditentukan berdasarkan masukan dari
Fakultas Bahasa dan Seni

Universitas Negeri Jakarta.

Lokasi yang ditentukan adalah

Pulau Tidung Kepulauan Seribu

DKI Jakarta.

2. Studi Pendahuluan

Setelah lokasi ditentukan, studi pendahuluan dilakukan terhadap profil Masyarakat Pulau Tidung yang ditinjau dari aspek sosial, budaya reliji dan lain- lain untuk mengetahui masalah-masalah yang dihadapi oleh masyarakat Pulau Tidung dan dalam rangka menggali potensi kearifan lokal yang dimiliki oleh masyarakat Pulau Tidung Kepulauna Seribu.

b) Tahap Kedua adalah Pelaksanaan Pengabdian kepada masyarakat yang diawali dengan evaluasi awal (pre test). Pre Test dilakukan terhadap seluruh peserta pelatihan dalam rangka mengukur tingkat pengetahuan dan pemahaman awal peserta terhadap berita palsu (Hoax). Kemudian dilanjutkan dengan penyampaian materi pada Pelatihan Literasi Media Mengantisipasi Berita Palsu (Hoax) Di Media Sosial dan diakhiri dengan evaluasi akhir (post test).

Materi pelatihan yang disampaikan adalah bagaimana mengidentifikasi berita palsu (hoax) dengan menggunkaan model Empowering 8 (E8) yang telah dimodifikasi dengan tahapan langkah-lamgkah sebagai berikut: 
DOI: https://doi.org/10.21009/sarwahita.161.07

P-ISSN: 0216-7484

E-ISSN: 2597-8926

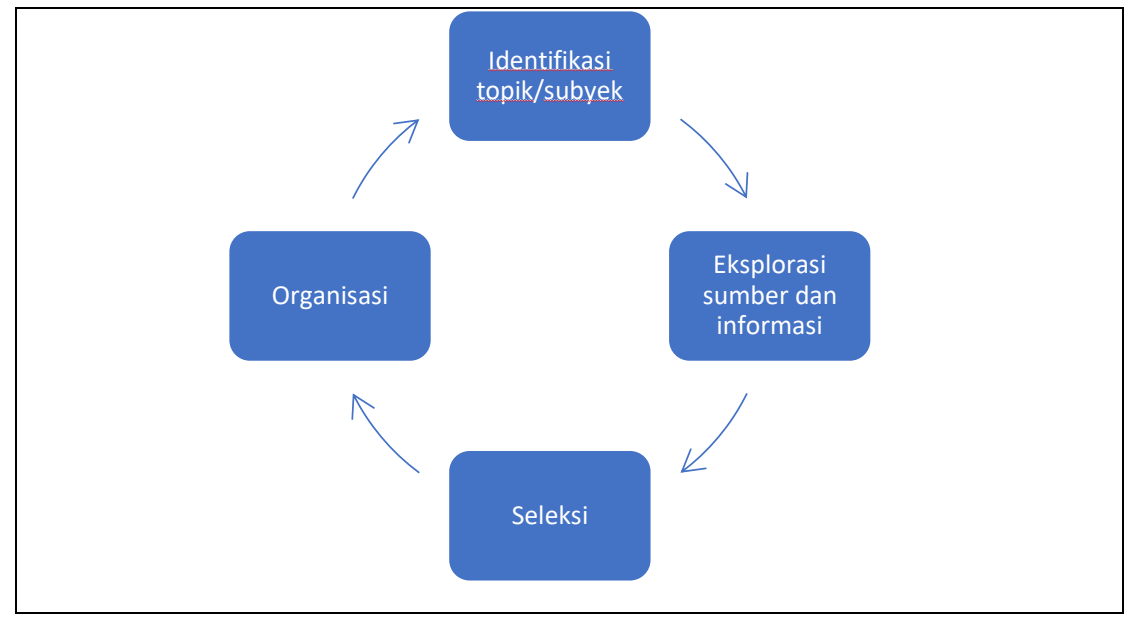

\section{Keterangan:}

1. Identifikasi topik/subyek Identifikasi topik/subyek sasaran audiens format yang relevan, jenis-jenis sumber.

2. Ekplorasi sumber dan informasi Eksplorasi sumber dan informasi yang sesuai dengan topik

3. Seleksi

Seleksi dan merekam informasi yang relevan, dan mengumpulkan kutipan-kutipan yang sesuai.

4. Organisasi

Organisasi, evaluasi dan menyusun infomasi menurut susunan yang logis, membedakan antara fakta dan pendapat, menggunakan alat bantu visual untuk membandingkan dan mengkontraskan informasi.

\section{HASIL DAN PEMBAHASAN}

Kegiatan Pengabdian kepada Masyarakat dengan judul Pelatihan Literasi Media Mengantisipasi Berita Palsu (Hoax) di Media Sosial dilaksanakan selama 2 (dua) hari sejak tanggal 16 s.d 17 November 2018. Peserta pelatihan terdiri dari masyarakat Kelurahan Pulau Tidung Kecamatan Kepulauan Seribu Selatan DKI Jakarta dengan jumlah peserta yang mengukuti pelatihan sebanyak 26 orang.

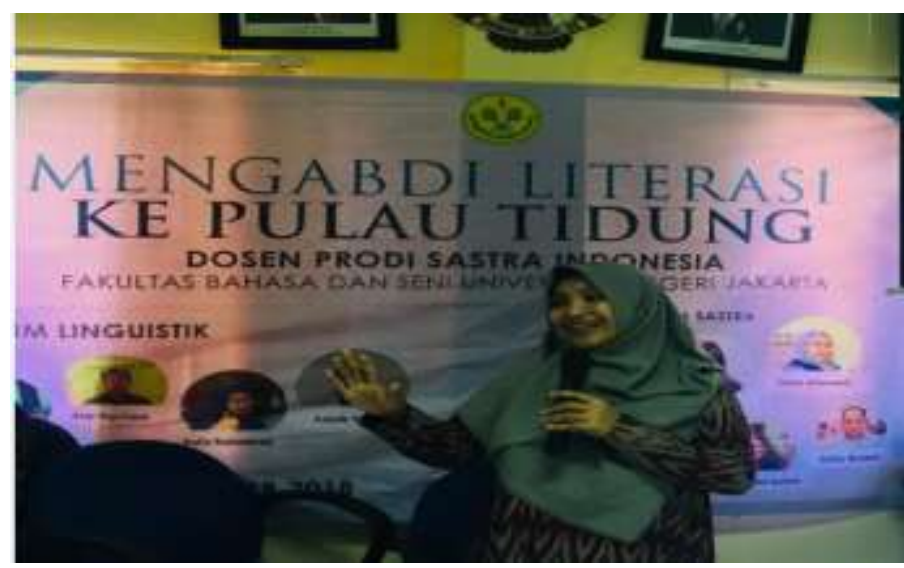

Gambar 1. Foto Saat Penyampaian Pelatihan Literasi Media Mengantisipasi 


\section{Berita Palsu (Hoax) di Media Sosial}

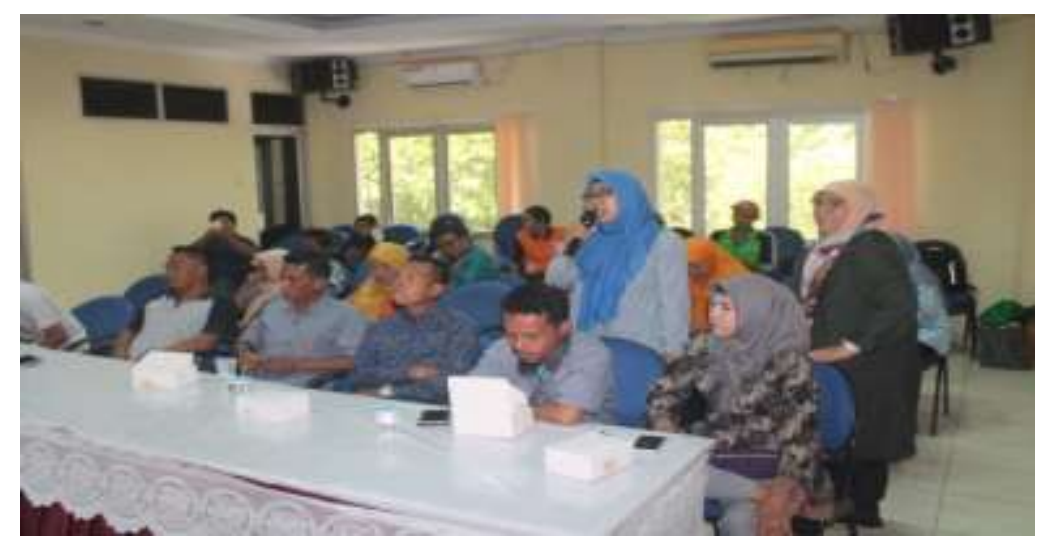

Gambar 2. Foto Peserta Pelatihan

Materi yang disampaikan pada Pelatihan ini meliputi:

1. Data statistik pengguna media informasi.

2. Definisi literasi media.

3. Mengapa literasi media penting

4. Regulasi yang melarang penyebaran infomasi palsu

5. Contoh kasus peneyebaran media palsu yang diproses kepolisian dan pengadilan

6. Literasi media sosial menggunkan pendekatan model Empowering 8 (E8)

Salah satu materi yang disampaikan dalam pelatihan ini adalah Literasi Media Sosial menggunakan pendekatan model Empowering 8 (E8) atau E8' di mana pendekatan yang digunakan adalah berupa pemecahan masalah untuk mengolah sumber informasi sebagai basis pembelajaran atau resource-based learning. Menurut Wijetunge dan Alahakoon (2009) melalui model Empowering 8 (E8) ini, kemampuan melakukan literasi informasi dengan penelusuran suatu berita hoax dilakukan melalui 8 tahapan praktik. Namun dalam pelaksanaan pengabdian masyarakat ini, model Empowering 8 (E8) dimodifikasi dengan hanya melakukan 4 tahapan langkah yakni:

1. Identifikasi topik/subjek, sasaran audiens, format yang relevan, jenisjenis sumber;

2. Eksplorasi sumber dan informasi yang sesuai dengan topik;

3. Seleksi dan merekam informasi yang relevan, dan mengumpulkan kutipan-kutipan yang sesuai;

4. Organisasi, evaluasi dan menyusun informasi menurut susunan yang logis, membedakan antara fakta dan pendapat, dan menggunakan alat bantu visual untuk membandingkan dan mengkontraskan informasi;

Untuk mengukur tingkat pengetahuan peserta Pelatihan, maka dilakukan serangkaian test yang dilakukan sebelum pelatihan dilakukan (Pre Test) dan setelah selesai Training (Post Test). 


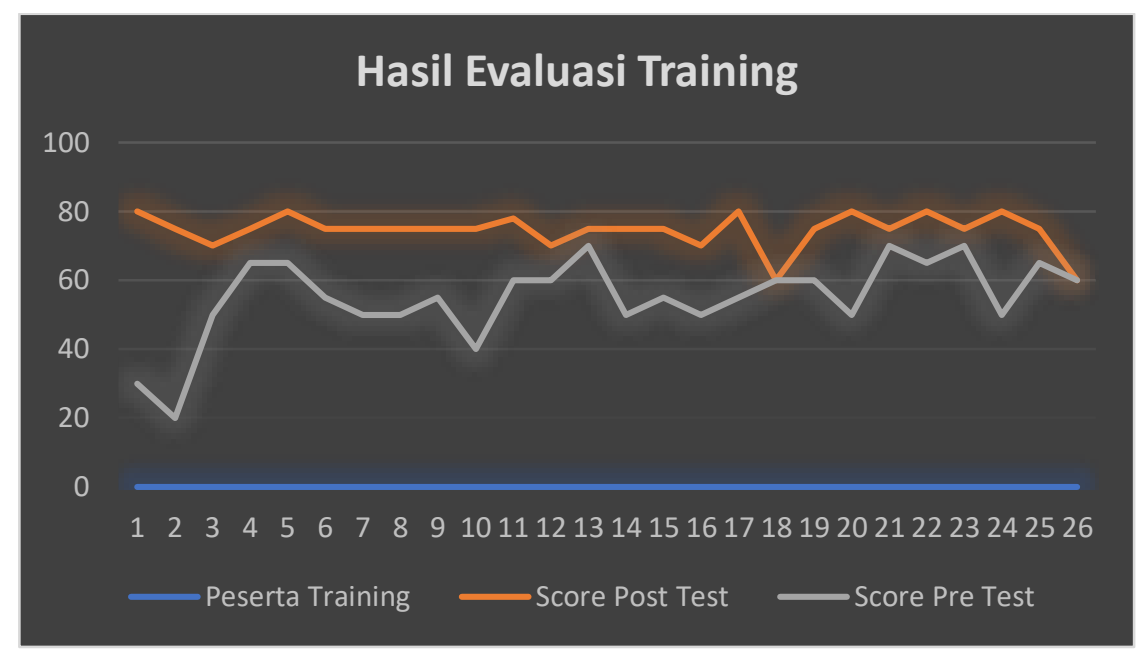

Gambar 3. Sebaran Nilai Evaluasi Training

Berdasarkan hasil pre test dan post test dilakukan terhadap 26 peserta training dengan total jumlah soal pre test maupun post test adalah sebanyak 20 soal dalam berbentuk pilihan ganda, di mana tiap soal yang benar akan memperoleh poin nilai sebanyak 5 poin, diperoleh hasil sebagai berikut:

1. Nilai rata-rata pre test yang diperoleh adalah 55 poin dengan rentang nilai 20 s.d 70 poin. Nilai terendah adalah 20 poin dengan nilai rata-rata 55 poin, mengindikasikan bahwa pemahaman peserta terhadap berita palsu (Hoax) di Media Sosial masih relative rendah sehingga pelatihan ini menjadi sangat penting untuk dilakukan agar masyarakat tidak salah dalam memahami berita yang beredar di masyarakat.

2. Setelah training selesai, seluruh peserta kembali mengikuti evaluasi akhir (post test) dengan jumlah soal dan tipe soal yang sama sebagaimana soal pre test. Hasil post test meningkat cukup signifikan, yakni sebanyak 19 poin dari nilai rata-rata nilai pre test yang semula rata-rata 55 poin dengan rentang nilai 20 s.d 70 poin, menjadi rata-rata 74 poin dengan rentang nilai 60 s.d 80 poin. Kondisi ini menunjukkan bahwa rata-rata pengetahuan peserta training mengalami peningkatan terutama terkait berita palsu (Hoax) di Media Sosial.

\section{PENUTUP}

Kegiatan pengabdian masyarakat ini menghasilkan beberapa kesimpulan sebagai berikut:

1. Peserta pelatihan ini terdiri dari masyarakat Kelurahan Pulau Tidung Kecamatan Kepulauan Seribu Selatan Kabupaten Kepulauan Seribu DKI Jakarta dengan jumlah peserta yang mengikuti pelatihan adalah sebanyak 26 orang.

2. Materi yang disampaikan pada Pelatihan literasi Media Mengantisipasi Berita Palsu (Hoax) di Media Sosial menggunakan pendekatan model Empowering 8 (E8) Model Empowering Eight (E8) dengan pendekatan pemecahan masalah untuk mengolah sumber 


\section{informasi sebagai basis pembelajaran atau resource-based learnin.}

3. Untuk mengukur tingkat pengetahuan peserta terkait tema pelatihan, dilakukan test pendahuluan (pre test) dan evaluasi akhir pasca training (Post test). Total jumlah soal pre test sama dengan post test yakni sebanyak 20 soal dalam berbentuk pilihan ganda, di mana tiap soal yang benar akan memperoleh poin nilai sebanyak 5 poin. Berdasarkan hasil post test dari 26 peserta yang mengikuti pelatihan, terdapat peningkatan nilai yang cukup signifikan, yakni sebanyak 19 poin dari nilai rata-rata nilai pre test adalah 55 poin dengan rentang nilai 20 s.d 70 poin, menjadi 74 poin dengan rentang nilai 60 s.d 80 poin.

Adapun saran yang dapat diberikan oleh tim pelaksana demi Pencegahan penyebaran hoax maka pelatihan serupa harus dilakukan secara massif bukan hanya melalui pelatihan ini namun juga melalui metode-metode lain yang lebih baik.

\section{DAFTAR PUSTAKA}

Considine, David. 1995. An Introduction to Media Literacy: The What, Why and How To's. The Journal of Media Literacy, Volume 41, Number 2.

Douglas, K. 2010. Budaya Media: Cultural Studies, Identitas, dan Politik : Antara Modern dan Posmodern. Yogyakarta: Jalasutra.

Kunandar, Alip. 2014. Model Literasi Media Pada Anak Dalam
Mencegah Konflik Sosial. Jurnal Komunikasi Profetik Vol. 7, No. 1, April 2014.

Nuril Hidayah, Cahya Suryani, Mizati Dewi Wasdiana. 2018. Pemetaan Hoaks Di Indonesia. Pilot project mafindo. Dirilis tgl. 30 September 2018

Rahadi, Dedi Rianto. 2017. Perilaku Pengguna Dan Informasi Hoax Di Media Sosial. Jurnal Manajemen dan Kewirausahaan Vol. 5 No. 1.

Setyaningsih, Rila. 2017. Model Literasi Media Berbasis Kearifan Lokal Pada Masyarakat Kampung Dongkelan Kauman Daerah Istimewa Yogyakarta. Komuniti, Vol. 9, No. 2, September 2017

Vibriza Juliswara. 2017. Mengembangkan Model Literasi Media yang Berkebhinnekaan dalam Menganalisis Informasi Berita Palsu (Hoax) di Media Sosial. Jurnal Pemikiran Sosiologi Volume 4 No. 2 , Agustus 2017.

Wijetunge, P, dan Alahakoon, U. 2009.

"Empowering 8: The Information Literacy Model Developed in Sri Lanka to Underpin Changing Education Paradigms of Sri Lanka”. Sri Lankan Journal of Librarianship and Information Management volume 1, No. 1:31-41. DOI: http://doi.org/10.4038/sllim.v1i1 .430 .

http://www.harianumum.com/berita/det ail/3980/Pulau-Tidung-Jadi-

Pilot-Project PengembanganWisata-di-Kepulauan-Seribu. 